\begin{tabular}{|l|l|l||}
\hline \multicolumn{2}{|c|}{ PublisherInfo } \\
\hline \hline PublisherName & $:$ & BioMed Central \\
\hline \hline PublisherLocation & $:$ & London \\
\hline \hline PublisherImprintName & $:$ & BioMed Central \\
\hline \hline
\end{tabular}

\title{
Extracellular matrix modulates mammary gland growth factor signalling
}

\begin{tabular}{|l|l|l||}
\hline \multicolumn{2}{|c||}{ ArticleInfo } \\
\hline \hline ArticleID & $:$ & 3634 \\
\hline \hline ArticleDOI & $:$ & $10.1186 /$ bcr-1999-66612 \\
\hline \hline ArticleCitationID & $:$ & 66612 \\
\hline \hline ArticleSequenceNumber & $:$ & 54 \\
\hline \hline ArticleCategory & $:$ & Paper Report \\
\hline \hline ArticleFirstPage & $:$ & 1 \\
\hline \hline ArticleLastPage & $:$ & 4 \\
\hline \hline & & RegistrationDate : 1999-9-22 \\
\hline ArticleHistory & $:$ & OnlineDate \\
\hline \hline ArticleCopyright & $:$ & Current Science Ltd1999-9-22 \\
\hline \hline ArticleGrants & $:$ & \\
\hline \hline ArticleContext & $:$ & 1305811 \\
\hline \hline
\end{tabular}




\section{Keywords}

basement membrane, collagen, EGF, insulin, mammary, signalling

\section{Introduction}

The interaction between a specific type of extracellular matrix (ECM) and growth factor (GF) receptor binding is known to be important for cell proliferation, migration, survival and differentiation. For example, mouse mammary epithelial cells (MMECs) require adhesion to a basement membrane (BM) matrix for both three-dimensional morphology and milk protein expression. However, the various mechanisms by which these signals are integrated have still to be elucidated. Knowledge of these mechanisms are of particular importance in neoplasia, where the extracellular environment, and thus the function of a particular GF may be altered.

\section{Aims}

To determine whether adhesion to a BM is a prerequisite for all GF function in breast epithelial cells.

\section{Comments}

This is an important paper because it emphasises the complexity and sensitivity of growth factor function and stresses how essential it is to establish an in vitro model that mimics as closely as possible the in vivo situation. Basement membrane/cell integrin interactions are becoming increasingly important in not only maintaining the normality of the breast but also giving us clues as to the effects of their disruption in neoplasia.

\section{Methods}


First passage MMECs from mid-pregnant mice were plated on dishes coated with either rat tail collagen I or a reconstituted BM matrix. The cells were cultured for $72 \mathrm{~h}$ in nutrient mixture F12 with additives. Following overnight starvation in Dulbecco?s modified Eagle's medium (MEM)/F12 containing only $1 \mu \mathrm{g} / \mathrm{ml}$ hydrocortisone, the cells were treated with EGF $(10 \mathrm{ng} / \mathrm{ml})$, insulin $(5 \mu \mathrm{g} / \mathrm{ml})$ or Interferon (IFN)- $\gamma$ (200 units/ml). After various time points, cells were lysed in the presence of protease inhibitors. Lysates were immunoprecipitated with 1-2 $\mu \mathrm{g}$ of appropriate antibody, subjected to SDSPAGE, blotted and probed with antibodies to phosphotyrosine (4G10), insulin receptor (IR), IRS-1, IRS-2, PI3K, EGFR, ErbB2, Erk, (all at $1 \mu \mathrm{g} / \mathrm{ml}$ ) and phospho-Erk (1:1000), Jak2 (1:5000), Stat3 (1:5000). Proteins were visualised by ECL and results are typical of three experiments.

\section{Results}

Numerous proteins were tyrosine phosphorylated in the MMECs cultured on both matrices with or without growth factor present. However, there were significant differences in the profiles following 15 and 30 minute treatments with EGF or insulin. Incubation with insulin resulted in the phosphorylation of its receptor (IR), using both substrates. However, IRS-1 and IRS-2 were only significantly phosphorylated when cells were plated on BM. The same BM specificity was true of an induced association of the IRS proteins with PI3 kinase. Preincubation with vanadate suggested that the response of cells cultured on collagen I was partially suppressed by the action of a protein tyrosine phosphatase. The addition of alkaline phosphatase to the IRS-1 immunoprecipitates from cells grown on both collagen I and BM showed that a shift in mobility of the IRS-1 protein on SDS-PAGE, following incubation with insulin, was due to additional serine-threonine phosphorylation. The effect of insulin on the phosphorylation of IR, IRS-1 and IRS-2 and on IRS association with PI3 kinase in cells on BM but not collagen I was sustained over several days, even after the removal of the hormone. In contrast to the results with PI3 kinase, incubation with insulin led to the phosphorylation or Erk1 and Erk2 in cells plated on both substrates.

\section{Discussion}

EGF was shown to induce more tyrosine phosphorylation of its receptor (EGFR) in cells grown on collagen I than BM. In contrast to the effect of insulin on IR, this was shown to be due to an increased level of EGFR. Exposure to EGF enhanced the phosphorylation of ErbB2 in cells on both subtrata but was more pronounced in those cultured on BM. This was not due to an effect on the amount of this receptor present. Erk1 and Erk2 were phosphorylated in cells on both matrices but to a greater extent on collagen I. This was thought to be due to the activity predominantly of phosphorylated EGFR in cells grown on collagen I and phosphorylated ErbB2 in cells grown on BM. IFN- $\gamma$, which is not known to be involved with normal mammary gland function, was used as a negative control. Treatment with this cytokine resulted in comparable levels of phosphorylated Jak2 and Stat3 being produced by cells on both collagen I and BM, whereas prolactin induced the phosphorylation of Jak2 only in cells grown on BM. 


\section{Additional information}

Mammary cell adhesion to ECM influences insulin and EGF signalling, but not that of IFN- $\gamma$, by distinct mechanisms. Insulin binding to its receptor leads to IR activation by phosphorylation which, in turn, brings about the association and phosphorylation of IRS to provide a docking site for downstream signalling molecules. In MMECs, although insulin is able to trigger tyrosine phosphorylation of its receptor in an ECM-independent manner, phosphorylation of IRS-1 and IRS-2 is significantly enhanced when cells are adhering to BM. Serine/threonine phosphorylation of IRS-1 and tyrosine phosphorylation of Erk1 and Erk2 were unaffected by differences in substrata. Thus, activation of the insulin receptor may occur through different pathways on collagen and BM. The authors discuss the role of phosphatases in modulating the effect of insulin on the phosphorylation of IRS-1 in cells grown on collagen I. Insulin and PI3 kinase are essential for milk production and this together with previous studies has shown that an association with a BM is required for this process to occur in mammary epithelial cells. Primary mouse mammary cells treated with EGF exhibited enhanced phosphorylation of EGFR and Erk this was found to be due to an increased level of receptor expression in cells grown on collagen I. Since breast epithelial cells are normally found in contact with a BM in vivo, the role of EGF in cell proliferation and migration in wound healing and neoplasia is discussed.

\section{References}

1. Lee Y-J, Streuli CH: Extracellular matrix selectively modulates the response of mammary epithelial cells to different soluble signalling ligands. J Biol Chem. 1999, 274: 22401-22408. 